\title{
Associating Statistical Relationship among Stock-sheet and Pieces in Rectangle Packing
}

\author{
Kawaljeet Singh and Leena Jain
}

\begin{abstract}
In the rectangle packing problem different ordered items (rectangular) compete for a stock sheet with an objective so that maximum sheet utilisation is obtained. The bill of material and stock sheet can be classified into three different categories (and so are objects) as regular when length/ width ratio is uniformly distributed $(1.25 \pm 0.25)$ (Wood, Glass industry), standard (length/ width ratio is uniformly distributed $(3 \pm 0.3)$ (Paper Industry) and tapered (length/ width ratio is uniformly distributed (6 \pm 1$)$ (VLSI Circuits, Adhesive Tapes). Likewise stock sheets can be the categorised as regular, standard or tapered. Thirty rules (heuristics) have been suggested by the authors in the revised/ reworked rectanglepacking algorithm suggested by Cheok-AYC Nee so as to generate different 120 feasible patterns and to draw various statistical inferences. In this paper, synthetically normally distributed bill of material has been generated to test the hypothesis if the nature of items and sheet put up with any correlation.
\end{abstract}

Index Terms-Greedy Approach, Heuristics algorithm, industrial applications, NP-complete problems, Rectangle Packing, Sheet Layout.1

\section{INTRODUCTION}

In the rectangle-packing problem, rectangular parts are placed onto a rectangular stock sheet, which is bigger in size in comparison to items with the aim of minimizing the unused space. This problem belongs to NP-complete problems class [1] where computation time for an exact solution increases with $\mathrm{N}$ and becomes rapidly prohibitive in cost as $\mathrm{N}$ increases [2]. The solution approach to these problems lies in reducing the exhaustive search of all possible arrangements of nesting the parts and subsequently checking upon the execution time. Usually, various heuristic rules are proposed to generate different patterns, which are generally the priority rules used to allocate patterns to the stock sheet sequentially. In this paper revised heuristic algorithm [3] is used to generate different pattern to sequence items both in ascending and in descending order on the basis of breadth, length, perimeter, area and aspect ratio (length/ width ratio). These sequenced items are then placed one-by-one onto the object from bottom-lower corner (sheet reference point) till the solution continues to be feasible. Both length-wise and breadth-wise orientations of the object and then first item placed onto it have been considered.

Manuscript received October 10, 2010.

Leena Jain, Ph. D., Research Scholar, University College of Engineering, Punjabi University, Patiala 147002, India(e-mail: jain_lina@yahoo.co.in/leenajain79@gmail.com).

Dr. Kawaljit Singh, Director, University Computer Centre, Punjabi University, Patiala 147002, India(e-mail: singhkawaljeet@pbi.ac.in/ singhkawaljeet@rediffmail.com).
Industrial practice and literature survey substantiate for varied distribution of length and breadth of the rectangular parts. This is because of numeral manufacturers in a job in wide-ranging industrial application areas. The wood [4], the glass [5] and the paper industry [6], [7] are mainly concerned with the cutting of regular figures (Fig. 1). On the other hand, in shipbuilding, textile [8] and leather industry [9], [10] irregular and arbitrary shaped items need to be packed [11] (Fig. 2 \& Fig. 3). In the VLSI applications the rectangular parts are generally skinny (aspect ratio of length/ width is large); whereas in furniture industry majority parts are regular (lengths and widths are of comparable dimensions). In sheet metal industry, a major portion of ordered pieces are generally standard in nature. In the simulation study, accordingly the items are classified into three different categories (and so are the objects) as regular, standard and tapered (defined later on in the research study). Literature survey substantiates that some researchers have suggested the uniform distribution [12] and others have suggested beta distribution [13] as shape distribution for length and width of rectangular parts. In the present study it is assumed that since the normal distribution comes close to fitting the actual observed frequency distributions of many phenomena, including human characteristics (weights, heights, IQs), outputs from physical processes (dimensions and yields) and other measures of interest related to industrial problems, accordingly, it is assumed that: -

- Breadth of each item is normally distributed with a presumed mean and the standard deviation as $1 / 4$ th of it.

- Length of each item is related to breadth as regular, standard and tapered.

There are three null hypotheses, one for different nature of objects; second for different nature of items laid on these objects and third one regarding the interaction. These are stated as follows: -

$\mathrm{H}_{01}$ : The means of the utilisation factor of sheet do not differ significantly with the nature of object (row factor).

$\mathrm{H}_{02}$ : The means of the utilisation factor of sheet do not differ significantly with the nature of the items laid on different nature of the objects (column factor).

$\mathrm{H}_{03}$ : The interaction between the two above stated factors is not significant.

The three stated hypothesis are tested for nine different combinations of objects and Items. 


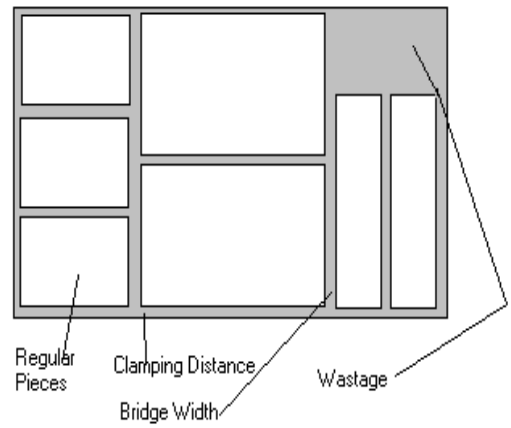

Fig1. Cutting of Regular Parts (All rectangular parts) from a Rectangular Sheet

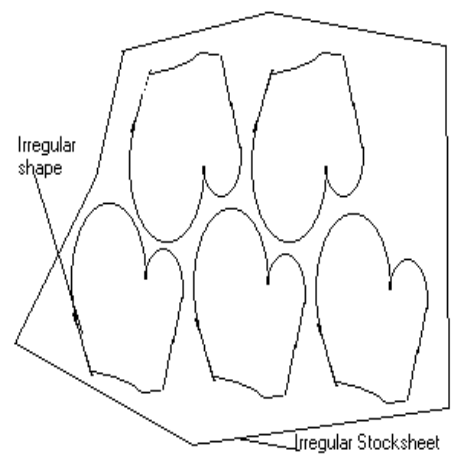

Fig 2. Cutting of Irregular Parts from an Irregular Stock Sheet

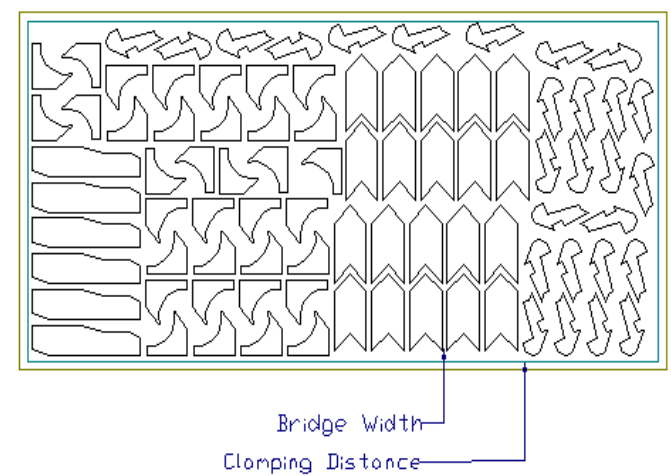

Fig 3. Cutting of Irregular Parts from a Rectangular Stock Sheet

\section{Details of Experimentation}

The classification criteria to categorise items/ objects as regular, standard or tapered is suggested on the basis of length/ breadth $(1 / \mathrm{b})$ ratio. The item/ object is categorised as regular if $(1 / \mathrm{b})$ ratio is in the range $(1.25 \pm 0.25)$; standard if $(1 / \mathrm{b})$ ratio is in the range ( $3 \pm 0.3)$ and tapered if $(1 / \mathrm{b})$ ratio ranges between $(6 \pm 1)$. Accordingly, nine different combinations of object/ items are investigated. For each combination of items and stock sheet, five set of samples are generated where breadth of the each rectangular part is normally distributed with mean $\mu=20$ and standard deviation $\sigma=5$. Thus, length of the items is calculated by multiplying breadth and uniformly distributed $1 / b$ ratio in the

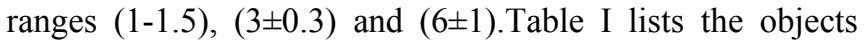
(stock sheets) of three different categories. Tables II-IV show the length and breadth of regular, standard and tapered items thus generated. Table $\mathrm{V}$ represents the quantity of different items. The total ordered items thus comes to 129 , which is a sufficiently large sample size. For an illustration, Table VI represents the performance of different heuristics for Sample 2 of regular items which are placed on regular sheet. Heuristic OL, OB indicates Orientation of Object in Length-wise and Breadth-wise direction. Heuristic IL, IB indicates Orientation of first item in Length-wise and Breadth-wise direction. PPL, PPB, PPD indicates sequencing Pivot Points along the Length, Breadth and Diagonal of the sheet and Heuristic OL-IL-D-SL-PPL indicates Orientation of Object is Length-wise and that of first Item placed is Length-wise; pieces are sequenced in Decreasing order on the basis of Sequencing basis Length and Pivot Points are sequenced in increasing order along the Length of the sheet; TPP is Total Piece Placed; UF is Sheet Utilization factor. Consequently, maximum sheet utilization factor $96.9 \%$ is obtained by applying heuristic OB-IL-D-SBPPL, OB-IL-D-SB-PPB and OB-IL-D-SB-PPD. Bold values in the tables identify the maximum utilization factor.

TABLE: I LENGTH AND BREADTH OF DIFFERENT TYPE OF OBJECT

\begin{tabular}{|c|c|c|}
\hline Object & L & W \\
\hline REGULAR & 225 & 150 \\
\hline STANDARD & 330 & 110 \\
\hline TAPERED & 490 & 70 \\
\hline \multicolumn{2}{|c|}{ L: Length W: Width }
\end{tabular}

TABLE II: DifFERENT FIVE DATA SETS FOR REGULAR ITEMS

\begin{tabular}{|c|c|c|c|c|c|c|c|c|c|}
\hline \multicolumn{2}{|c|}{ Sample :1 } & \multicolumn{2}{|c|}{ Sample :2 } & \multicolumn{2}{|c|}{ Sample :3 } & \multicolumn{2}{c|}{ Sample :4 } & \multicolumn{2}{c|}{ Sample :5 } \\
\hline L & B & L & B & L & B & L & B & L & B \\
\hline 7 & 6 & 18 & 14 & 19 & 15 & 12 & 10 & 18 & 12 \\
\hline 11 & 11 & 22 & 15 & 23 & 17 & 15 & 12 & 13 & 13 \\
\hline 16 & 13 & 23 & 17 & 27 & 18 & 18 & 14 & 21 & 14 \\
\hline 19 & 14 & 25 & 18 & 21 & 19 & 15 & 15 & 22 & 15 \\
\hline 26 & 18 & 20 & 19 & 21 & 20 & 21 & 17 & 23 & 16 \\
\hline 23 & 19 & 25 & 20 & 26 & 21 & 24 & 18 & 23 & 17 \\
\hline 20 & 20 & 26 & 21 & 27 & 22 & 25 & 19 & 28 & 20 \\
\hline 29 & 21 & 25 & 22 & 29 & 23 & 29 & 20 & 24 & 21 \\
\hline 29 & 22 & 29 & 23 & 28 & 24 & 40 & 27 & 23 & 22 \\
\hline 25 & 23 & 25 & 24 & 27 & 25 & 42 & 29 & 32 & 23 \\
\hline 35 & 24 & 35 & 25 & 32 & 29 & 32 & 30 & 31 & 25 \\
\hline
\end{tabular}

TABLE III: DIFFERENT FIVE DATA SETS FOR STANDARD ITEMS

\begin{tabular}{|c|c|c|c|c|c|c|c|c|c|}
\hline \multicolumn{2}{|c|}{ Sample :1 } & \multicolumn{2}{|c|}{ Sample :2 } & \multicolumn{2}{c|}{ Sample :3 } & \multicolumn{2}{c|}{ Sample :4 } & \multicolumn{2}{c|}{ Sample :5 } \\
\hline L & B & L & B & L & B & L & B & L & B \\
\hline 19 & 6 & 43 & 14 & 41 & 15 & 29 & 10 & 34 & 12 \\
\hline 30 & 11 & 43 & 15 & 51 & 17 & 39 & 12 & 36 & 13 \\
\hline 42 & 13 & 53 & 17 & 50 & 18 & 43 & 14 & 43 & 14 \\
\hline 39 & 14 & 57 & 18 & 52 & 19 & 47 & 15 & 48 & 15 \\
\hline 52 & 18 & 61 & 19 & 55 & 20 & 56 & 17 & 46 & 16 \\
\hline 54 & 19 & 62 & 20 & 58 & 21 & 55 & 18 & 50 & 17 \\
\hline 58 & 20 & 64 & 21 & 71 & 22 & 53 & 19 & 60 & 20 \\
\hline 60 & 21 & 66 & 22 & 75 & 23 & 64 & 20 & 62 & 21 \\
\hline 65 & 22 & 63 & 23 & 71 & 24 & 82 & 27 & 69 & 22 \\
\hline 69 & 23 & 66 & 24 & 72 & 25 & 91 & 29 & 72 & 23 \\
\hline 76 & 24 & 71 & 25 & 85 & 29 & 90 & 30 & 69 & 25 \\
\hline
\end{tabular}


TABLE IV: DIFFERENT FIVE DATA SETS FOR TAPERED ITEMS

\begin{tabular}{|c|c|c|c|c|c|c|c|c|c|}
\hline \multicolumn{2}{|c|}{ Sample :1 } & \multicolumn{2}{|c|}{ Sample :2 } & \multicolumn{2}{c|}{ Sample :3 } & \multicolumn{2}{c|}{ Sample :4 } & \multicolumn{2}{|c|}{ Sample :5 } \\
\hline L & B & L & B & L & B & L & B & L & B \\
\hline 35 & 6 & 79 & 14 & 79 & 15 & 69 & 10 & 66 & 12 \\
\hline 70 & 11 & 79 & 15 & 101 & 17 & 77 & 12 & 78 & 13 \\
\hline 76 & 13 & 96 & 17 & 114 & 18 & 85 & 14 & 98 & 14 \\
\hline 89 & 14 & 122 & 18 & 133 & 19 & 103 & 15 & 79 & 15 \\
\hline 107 & 18 & 114 & 19 & 136 & 20 & 117 & 17 & 84 & 16 \\
\hline 117 & 19 & 108 & 20 & 137 & 21 & 93 & 18 & 109 & 17 \\
\hline 133 & 20 & 113 & 21 & 125 & 22 & 100 & 19 & 130 & 20 \\
\hline 130 & 21 & 137 & 22 & 141 & 23 & 127 & 20 & 121 & 21 \\
\hline 121 & 22 & 133 & 23 & 167 & 24 & 161 & 27 & 119 & 22 \\
\hline 139 & 23 & 148 & 24 & 157 & 25 & 173 & 29 & 159 & 23 \\
\hline 145 & 24 & 152 & 25 & 159 & 29 & 159 & 30 & 172 & 25 \\
\hline
\end{tabular}

TABLE V: QUANTITY VECTOR FOR DIFFERENT TYPE OF ITEMS

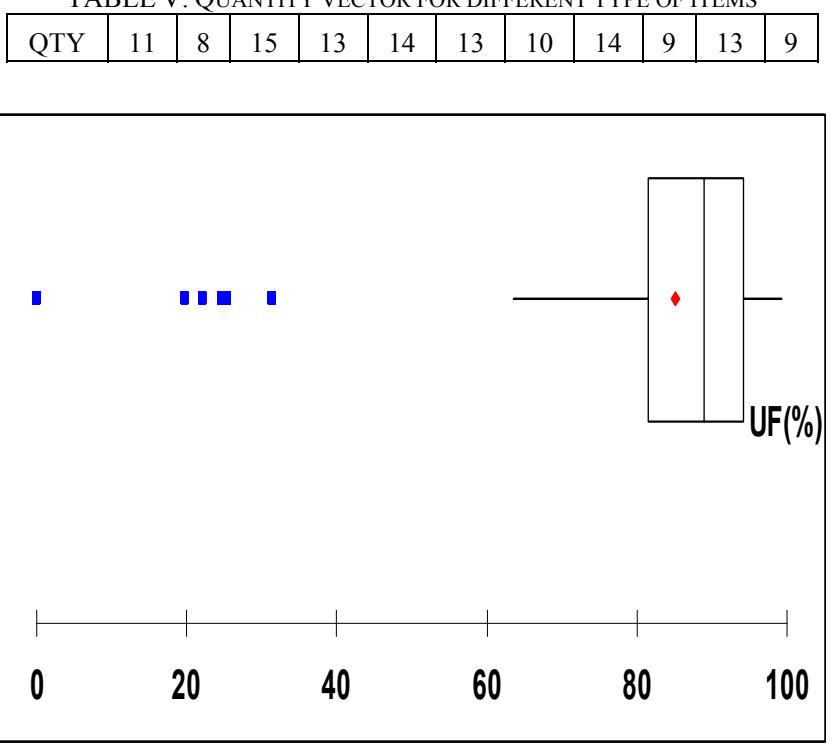

Fig 4. Box plot (of 5400 values)

\section{RESULTS AND DISCUSSIONS}

Five different samples for each form of object-item combination have been considered in this empirical study. The best UF\% for all 120 heuristics for the 45 sets has been tabulated. Refer to the Table VII. Corresponding statistical summary is available in the Table VIII. The Box-Plot graph has been obtained for 5400 such sheet utilisation factors (Fig 4). Few outliers were observed indicating inferior sheet utilisation factors. It has been observed that among the set of $5400 \mathrm{UF} \%$ values, just $3.56 \%$ values are outliers and $96.44 \%$ values are similar in nature (Fig 5). Fig 6 shows the Histogram for all 5400 cases with their UF (\%). A few mock-up cases in which items are tapered and breadth of the tapered object is small have proved to be failure. On scrutinising it has been found that these poor results are because of erroneous data sets where items to be placed happen to be larger in comparison to the object on which these are to be placed. So as to carry out the study, best UF\% of each experiment has been considered. Fig 7-9 represents the layouts of maximum Utilization Factor (UF \%) when regular items laid on regular object, standard object and Tapered Object. Whereas Fig 10-12 represent the layouts of maximum Utilization Factor (UF \%) when Standard items laid on regular object, standard object and Tapered Object. Fig 13-15 represent the layouts of maximum Utilisation Factor (UF\%) when Tapered items laid on regular object, standard object and Tapered Object .Refer to the Table-VII that contains top UF\% value of each of the 45 simulations. The data about sheet utilizations has been classified according to two characteristics/ factors. These are the nature of the object vis-à-vis different forms of items that are to be laid on these objects. For this two-way classified data there are five different data values related to sheet utilisation factors associated with five different data cases/ replications that belong to a particular normally distributed population. So, the empirical study involved observing the sheet utilisation factor for different combinations of objects and items and five observations/ responses has been obtained from the experiment. The populations, from which the samples were selected, are assumed to be normally distributed and have the same variance. Also, all the five samples are assumed to be random and independent of each other. A statistical test for comparing the means of more than two groups so as to investigate that means are likely to be same or different is exactly the scope of problem. Also, it is possible to estimate the interaction or the joint effect of the nature of the object/ items on the sheet utilization factor. Two-way ANOVA with replication is exactly the statistical test case that is applicable to study [14], [15]. There are three null hypotheses, one for each factor and another one regarding the interaction states as $\mathrm{H}_{01}, \mathrm{H}_{02}$ and $\mathrm{H}_{03}$. From the summary table (Table VIII) we can read the mean and variance of the sheet utilization factor corresponding to the three different forms of items to the three different types of objects. The last table having the title TOTAL gives the mean and variance of all the nine observations under each column for Regular, Standard and Tapered. These column headings are common to all the tables. In the ANOVA table (Table IX), the first source of variation is given as SAMPLE, which corresponds to the nature of the object and the second source corresponds to the nature of ITEM. The F-value corresponding to the Objects and Items are lower than the corresponding critical values and hence we conclude that the both Object and Item have no significant effect on the sheet utilisation factor. The third source of variation is the Interaction, which is an indication of the joint effect of Object and Items on the sheet utilisation factor. The effect is not significant as the F-value obtained is lower than critical value. Note that for all sort of statistical graphs/ analysis demo versions/ supporting disks along with books as Minitab, StatPro and Excel have been used. 
TABLE VI: PERFORMANCES OF DifFERENT HEURISTICS FOR SAMPLE 2 (Regular Items placed on Regular Sheet)

\begin{tabular}{|c|c|c|c|c|c|c|c|c|c|c|}
\hline \multirow[b]{2}{*}{$\#$} & \multirow[b]{2}{*}{ ORDER } & \multirow[b]{2}{*}{ SPP } & \multicolumn{2}{|c|}{ OL-IL } & \multicolumn{2}{|c|}{ OB-IL } & \multicolumn{2}{|c|}{ OL-IB } & \multicolumn{2}{|c|}{ OB-IB } \\
\hline & & & TPP & $\begin{array}{c}\text { UF } \\
(\%) \\
\end{array}$ & TPP & $\begin{array}{c}\text { UF } \\
(\%) \\
\end{array}$ & TPP & $\begin{array}{c}\text { UF } \\
(\%) \\
\end{array}$ & TPP & $\begin{array}{c}\text { UF } \\
(\%) \\
\end{array}$ \\
\hline I. & D-SA & PPL & 53 & 96.65 & 53 & 96.65 & 45 & 87.01 & 49 & 92.47 \\
\hline II. & D-SA & PPB & 53 & 96.65 & 53 & 96.65 & 45 & 87.01 & 49 & 92.47 \\
\hline III. & D-SA & PPD & 53 & 96.65 & 53 & 96.65 & 45 & 87.01 & 49 & 92.47 \\
\hline IV. & D-SAR & PPL & 65 & 90.38 & 62 & 85.94 & 64 & 89.89 & 63 & 86.92 \\
\hline V. & D-SAR & PPB & 63 & 86.43 & 62 & 85.94 & 64 & 89.89 & 63 & 86.92 \\
\hline VI. & D-SAR & PPD & 65 & 90.38 & 62 & 85.94 & 64 & 89.89 & 63 & 86.92 \\
\hline VII. & D-SB & PPL & 51 & 94.47 & 52 & 96.93 & 50 & 92.99 & 50 & 94.36 \\
\hline VIII. & D-SB & PPB & 51 & 94.47 & 52 & 96.93 & 50 & 92.99 & 50 & 94.36 \\
\hline IX. & D-SB & PPD & 51 & 94.47 & 52 & 96.93 & 50 & 92.99 & 50 & 94.36 \\
\hline $\mathrm{X}$. & D-SL & PPL & 53 & 95.21 & 49 & 92.68 & 48 & 88.55 & 50 & 92.77 \\
\hline XI. & D-SL & PPB & 53 & 95.21 & 53 & 95.9 & 48 & 88.55 & 50 & 92.77 \\
\hline XII. & D-SL & PPD & 53 & 95.21 & 49 & 92.68 & 48 & 88.55 & 50 & 92.77 \\
\hline XIII. & D-SP & PPL & 53 & 96.65 & 53 & 96.65 & 45 & 87.01 & 49 & 92.47 \\
\hline XIV. & D-SP & PPB & 53 & 96.65 & 53 & 96.65 & 45 & 87.01 & 49 & 92.47 \\
\hline XV. & D-SP & PPD & 53 & 96.65 & 53 & 96.65 & 45 & 87.01 & 49 & 92.47 \\
\hline XVI. & I-SA & PPL & 73 & 84.29 & 75 & 87.39 & 71 & 81.32 & 74 & 85.77 \\
\hline XVII. & I-SA & PPB & 73 & 84.29 & 75 & 87.39 & 71 & 81.32 & 74 & 85.77 \\
\hline XVIII. & I-SA & PPD & 73 & 84.29 & 75 & 87.39 & 71 & 81.32 & 74 & 85.77 \\
\hline XIX. & I-SAR & PPL & 62 & 91.96 & 67 & 93.49 & 62 & 91.96 & 67 & 93.49 \\
\hline $\mathrm{XX}$. & I-SAR & PPB & 62 & 91.96 & 67 & 93.49 & 62 & 91.96 & 67 & 93.49 \\
\hline XXI. & I-SAR & PPD & 62 & 91.96 & 67 & 93.49 & 62 & 91.96 & 67 & 93.49 \\
\hline XXII. & $\mathrm{I}-\mathrm{SB}$ & PPL & 72 & 82.51 & 75 & 87.39 & 72 & 82.81 & 71 & 81.32 \\
\hline XXIII. & I-SB & PPB & 72 & 82.51 & 75 & 87.39 & 72 & 82.81 & 72 & 82.81 \\
\hline XXIV. & I-SB & PPD & 72 & 82.51 & 75 & 87.39 & 72 & 82.81 & 72 & 82.81 \\
\hline XXV. & I-SL & PPL & 70 & 84.14 & 66 & 80.14 & 69 & 84.58 & 71 & 87.4 \\
\hline XXVI. & I-SL & PPB & 70 & 84.14 & 66 & 80.14 & 69 & 84.58 & 72 & 89.62 \\
\hline XXVII. & I-SL & PPD & 70 & 84.14 & 66 & 80.14 & 69 & 84.58 & 71 & 87.4 \\
\hline XXVIII. & I-SP & PPL & 73 & 84.29 & 75 & 87.39 & 71 & 81.32 & 74 & 85.77 \\
\hline XXIX. & I-SP & PPB & 73 & 84.29 & 75 & 87.39 & 71 & 81.32 & 74 & 85.77 \\
\hline XXX. & I-SP & PPD & 73 & 84.29 & 75 & 87.39 & 71 & 81.32 & 74 & 85.77 \\
\hline
\end{tabular}

TABLE VII: BEST UTILIZATION FACTOR (\%) (ALL 45 SETS)

\begin{tabular}{|c|c|c|c|c|}
\hline Object & \multicolumn{4}{|c|}{ Item } \\
\hline \multirow{6}{*}{ 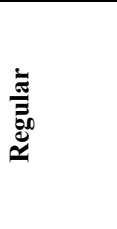 } & & Regular & Standard & Tapered \\
\hline & Sample I & 97.680 & 96.630 & 97.780 \\
\hline & Sample II & 96.930 & 95.130 & 99.130 \\
\hline & Sample III & 97.290 & 97.030 & 96.050 \\
\hline & Sample IV & 98.570 & 98.200 & 95.270 \\
\hline & Sample V & 98.360 & 97.410 & 97.200 \\
\hline \multirow{6}{*}{ 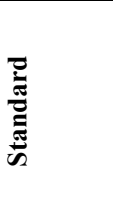 } & & Regular & Standard & Tapered \\
\hline & Sample I & 98.840 & 98.730 & 97.600 \\
\hline & Sample II & 96.970 & 95.510 & 98.120 \\
\hline & Sample III & 94.480 & 96.940 & 94.080 \\
\hline & Sample IV & 98.260 & 98.360 & 99.180 \\
\hline & Sample V & 97.630 & 97.750 & 98.970 \\
\hline \multirow{6}{*}{ 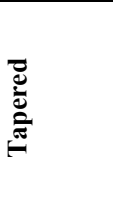 } & & Regular & Standard & Tapered \\
\hline & Sample I & 97.720 & 98.860 & 98.650 \\
\hline & Sample II & 99.210 & 96.520 & 96.170 \\
\hline & Sample III & 97.520 & 96.210 & 91.880 \\
\hline & Sample IV & 99.060 & 97.740 & 97.520 \\
\hline & Sample V & 98.300 & 97.570 & 98.910 \\
\hline
\end{tabular}


TABLE VIII: STATISTICAL SUMMARY

(For each Combination of Item and Object)

\begin{tabular}{|c|c|c|c|}
\hline Summary & Regular Item & Standard Item & Tapered Item \\
\hline & \multicolumn{3}{|c|}{ Object: Regular } \\
\hline Count & 5 & 5 & 5 \\
\hline Sum & 488.83 & 484.4 & 485.43 \\
\hline Average & 97.766 & 96.88 & 97.086 \\
\hline Variance & 0.48303 & 1.2927 & 2.26093 \\
\hline & \multicolumn{3}{|c|}{ Object: Standard } \\
\hline Count & 5 & 5 & 5 \\
\hline Sum & 486.18 & 487.29 & 487.95 \\
\hline Average & 97.236 & 97.458 & 97.59 \\
\hline Variance & 2.86073 & 1.64497 & 4.2584 \\
\hline & \multicolumn{3}{|c|}{ Object: Tapered } \\
\hline Count & 5 & 5 & 5 \\
\hline Sum & 491.81 & 486.9 & 483.13 \\
\hline Average & 98.362 & 97.38 & 96.626 \\
\hline Variance & 0.58282 & 1.11615 & 8.21123 \\
\hline & & TOTAL \\
\hline Count & 15 & 15 & 15 \\
\hline Sum & 1466.82 & 1458.59 & 1456.51 \\
\hline Average & 97.788 & 97.23933 & 97.1007 \\
\hline Variance & 1.34855 & 1.228492 & 4.37479 \\
\hline
\end{tabular}

TABLE IX: TWO WAY ANOVA TABLE

\begin{tabular}{|c|c|c|c|c|c|c|}
\hline \multicolumn{7}{|c|}{ ANOVA: Two-factor with Replication } \\
\hline $\begin{array}{c}\text { Source of } \\
\text { variation }\end{array}$ & SS & DF & MS & F & p-value & F crit \\
\hline Sample & 0.39792 & 2 & 0.19896 & 0.07885 & 0.92434 & 3.25944 \\
\hline Columns & 3.96345 & 2 & 1.98173 & 0.78533 & 0.46363 & 3.25944 \\
\hline Interaction & 6.08387 & 4 & 1.52097 & 0.60274 & 0.66313 & 2.63353 \\
\hline Within & 90.8438 & 36 & 2.52344 & & & \\
\hline Total & 101.289 & 44 & & & & \\
\hline
\end{tabular}

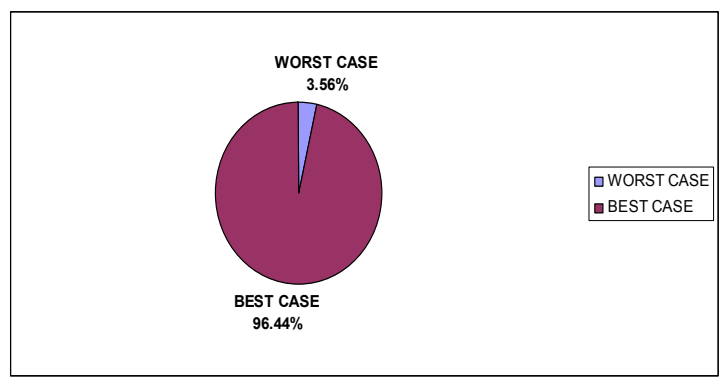

Fig 5. Pie-Graph erroneous/successful test cases for empirical study

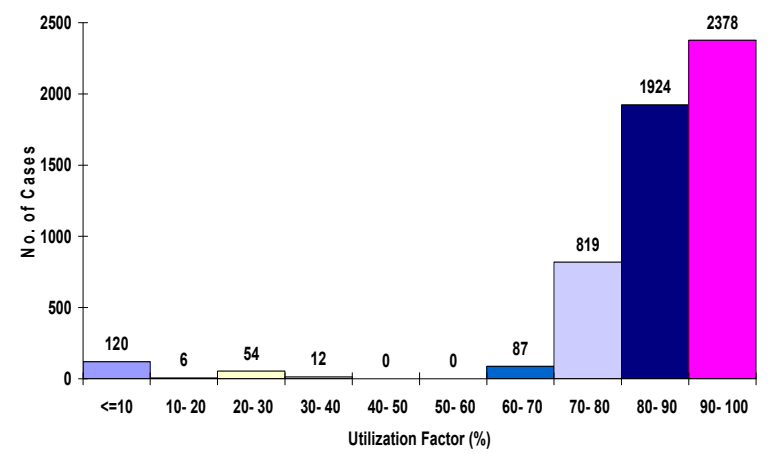

Fig 6. Histogram (of 5400 Values)

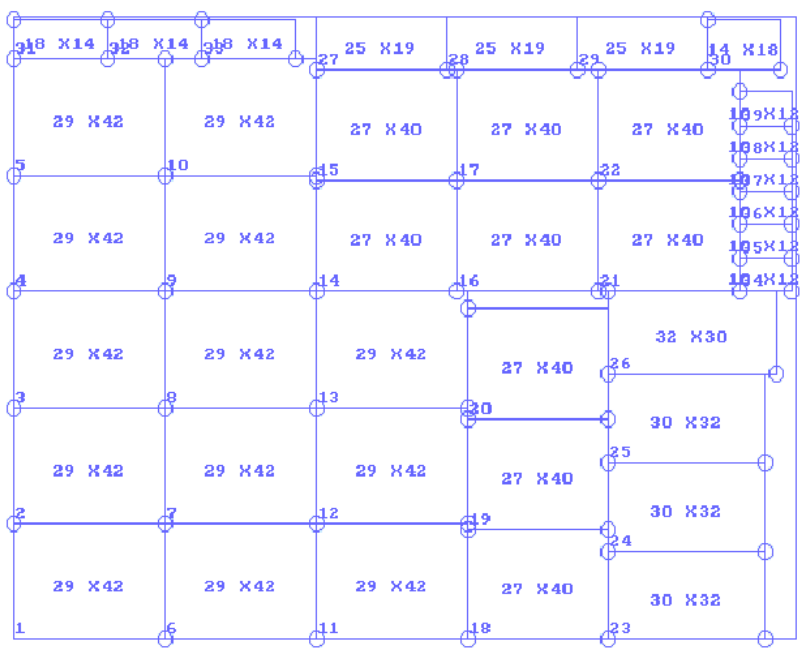

Fig 7. Regular items lay on regular object UF (\%): $98.57 \%$ TPP: 39 


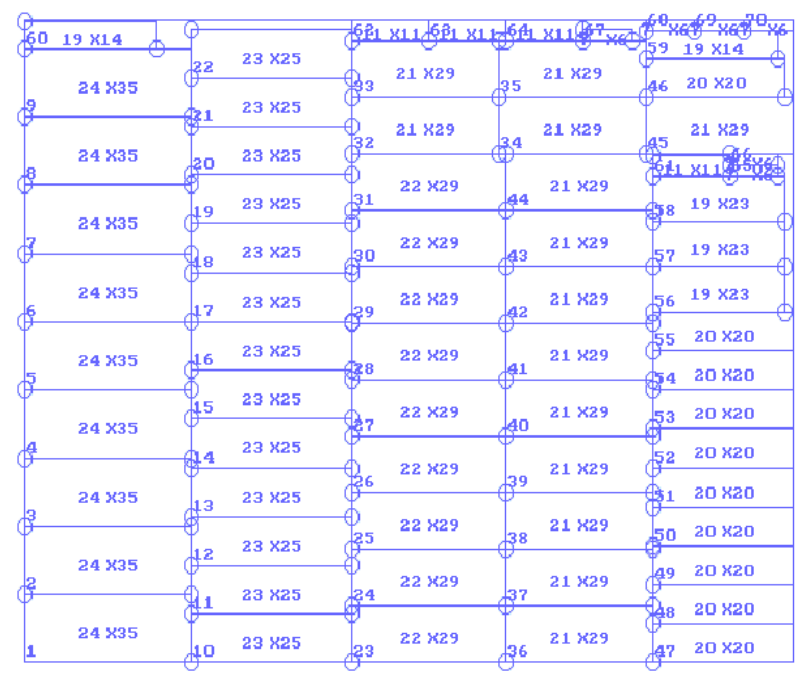

Fig 8. Regular Items lay on standard sheet UF (\%): $98.84 \%$ TPP: 70

\begin{tabular}{|c|c|c|c|c|c|}
\hline 16 & $25 \times 24$ & 34 & $22 \times 25$ & 37 & $22 \times 25$ \\
\hline 15 & $25 \times 24$ & 33 & $22 \times 25$ & 36 & $22 \times 25$ \\
\hline 14 & 25 K24 & 32 & $22 \times 25$ & 5 & $22 \times 25$ \\
\hline 13 & $25 \times 24$ & 31 & $23 \times 29$ & 47 & $21 \times 26$ \\
\hline 12 & $25 \times 24$ & 30 & 23 829 & & 21826 \\
\hline 11 & $25 \times 24$ & 9 & $23 \times 29$ & 45 & $22 \times 25$ \\
\hline \multirow[b]{2}{*}{9} & \multirow{2}{*}{$25 \times 35$} & 8 & $23 \times 29$ & 44 & $22 \times 25$ \\
\hline & & & $23 \times 29$ & 43 & 22825 \\
\hline 8 & $25 \times 35$ & & \multirow{2}{*}{$23 \times 29$} & 42 & $22 \times 25$ \\
\hline \multirow{2}{*}{3} & \multirow{2}{*}{$25 \times 35$} & & & & $22 \times 25$ \\
\hline & & 5 & $23 \times 29$ & 10 & $22 \times 25$ \\
\hline 6 & $25 \times 35$ & 34 & $23 \times 29$ & 89 & $22 \times 25$ \\
\hline \multirow{2}{*}{5} & \multirow[t]{2}{*}{$25 \times 35$} & 23 & $23 \times 29$ & 38 & $22 \times 25$ \\
\hline & & 22 & $24 \times 25$ & 53 & $20 \times 19$ \\
\hline \multirow{2}{*}{ 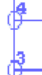 } & $25 \times 35$ & 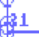 & $24 \times 35$ & 52 & $21 \times 26$ \\
\hline & $25 \times 35$ & 30 & $24 \mathrm{Ka25}$ & 51 & $21 \times 26$ \\
\hline \multirow{2}{*}{$2^{2}$} & \multirow{2}{*}{$25 \times 35$} & tis & $24 \times 25$ & 50 & $21 \times 26$ \\
\hline & & 18 & $24 \times 25$ & 49 & $21 \times 26$ \\
\hline 1 & $25 \times 35$ & 47 & $24 \times 25$ & 48 & $21 \times 26$ \\
\hline
\end{tabular}

Fig 9. Regular items lay on Tapered Sheet UF (\%): $99.210 \%$ TPP: 53

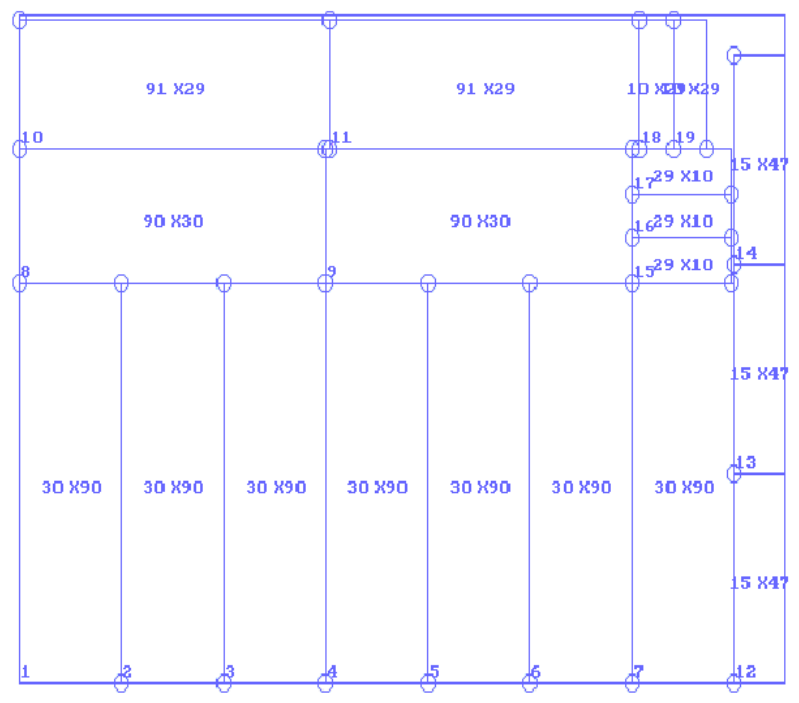

Fig 10. Standard items lay on Regular Sheet UF (\%): $98.20 \%$ TPP: 19

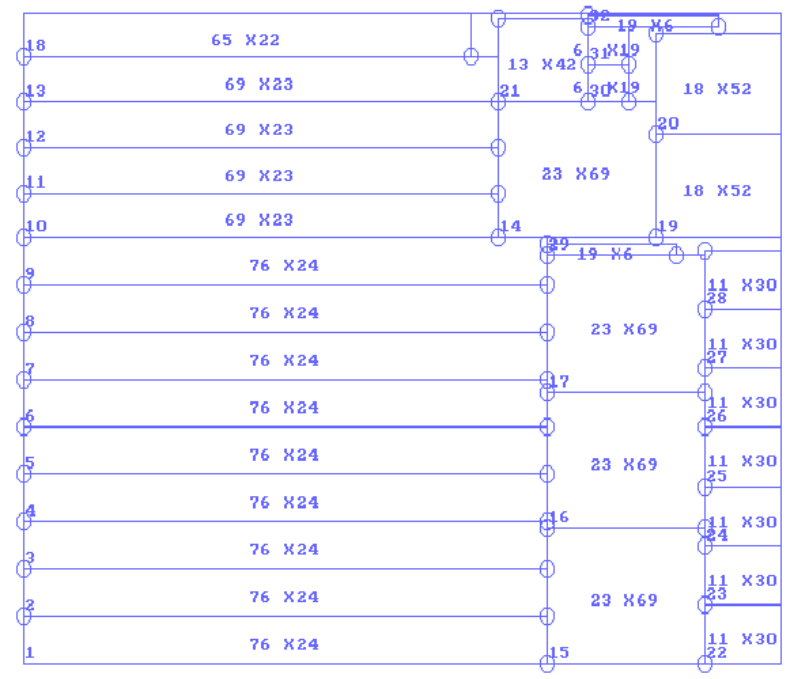

Fig 11. Standard items lay on standard Sheet UF (\%): 98.42\% TPP: 32

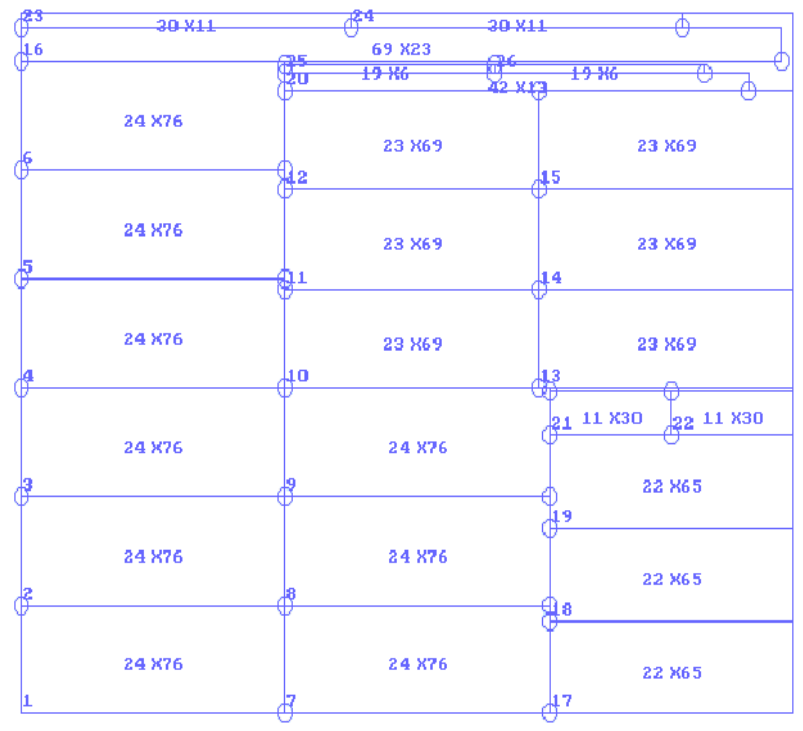

Fig 12. Standard items lay on tapered Sheet UF (\%): 98.86\% TPP: 26

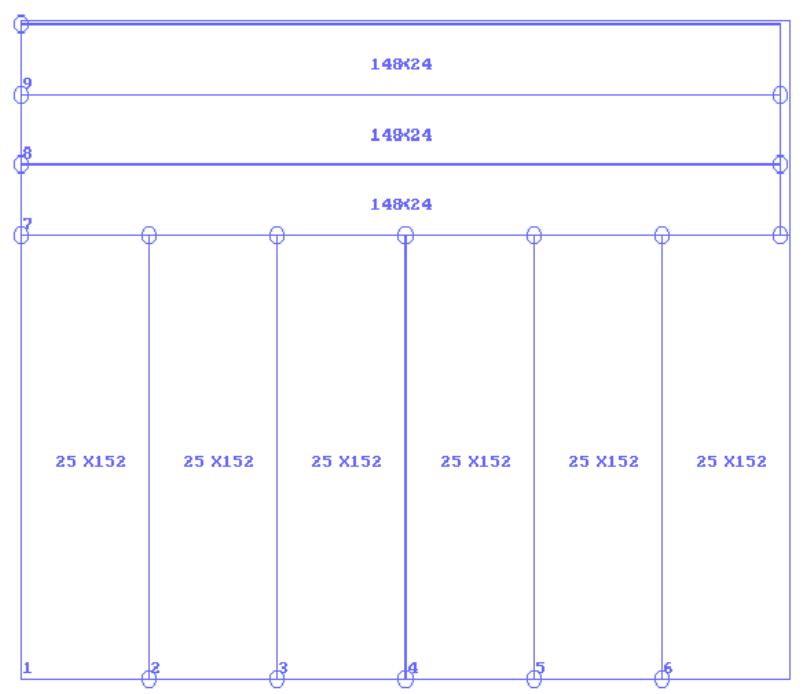

Fig 13. Tapered items lay on regular sheet UF (\%): 99.13\% TPP: 9 


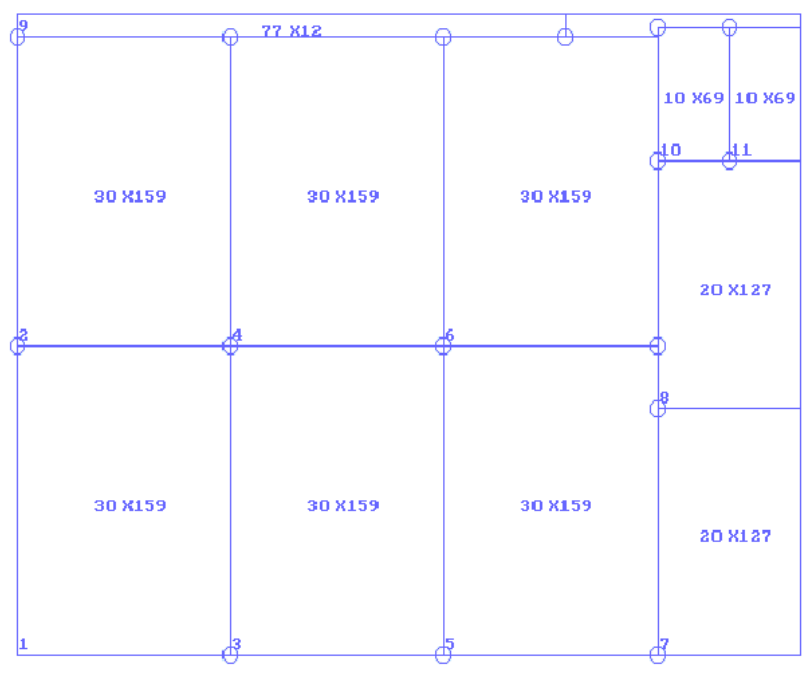

Fig 14. Tapered items lay on Standard Sheet UF (\%): 99.18\% TPP: 11

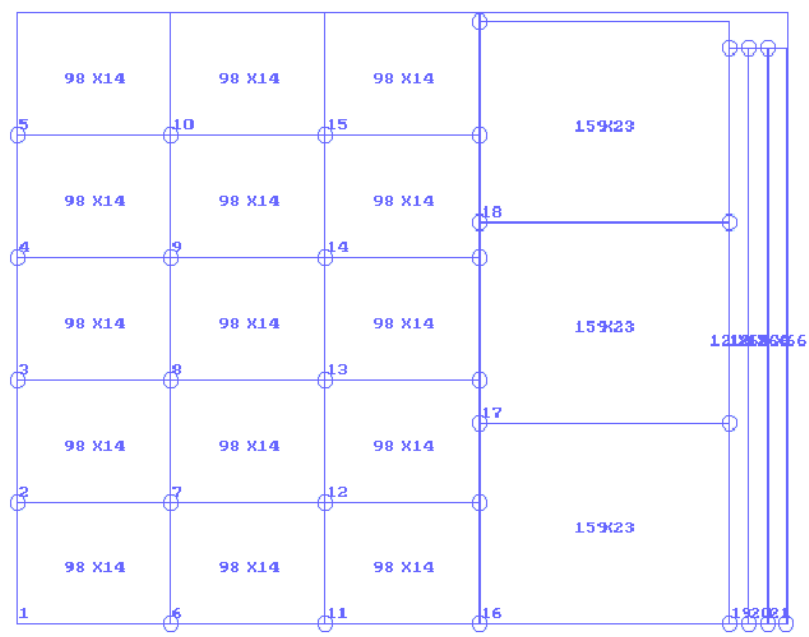

Fig 15. Tapered items lay on Tapered Sheet UF (\%): $98.910 \%$ TPP: 21

\section{IV.CONCLUSION}

It is common in the rectangle packing problem to observe different forms of objects/ items. Intuitively, the bill of material and stock sheet can be classified into three different categories (and so are objects) as regular when length/ width ratio is uniformly distributed $(1.25 \pm 0.25$ ) (Wood, Glass industry), standard (length/ width ratio is uniformly distributed ( $3 \pm 0.3)$ (Paper Industry) and tapered (length/ width ratio is uniformly distributed $(6 \pm 1)$ (VLSI Circuits, Adhesive Tapes). Likewise stock sheets can be the categorised as regular, standard or tapered. In this paper, synthetically normally distributed bill of material had been generated to test the hypothesis if the nature of items and sheet put up with any correlation. Almost $96 \%$ of the synthetic cases have been found to be well-matched to work out the relationship among the different form of objects and items. Two-way ANOVA test with replications was applied to look for the acceptance of null hypothesis. It is concluded that the nature of Object and/ or Item (or even their joint effect) have no significant effect on the sheet utilisation factor. Hence, it is recommended strongly to obtain UF\% value for all proposed (120) heuristics irrespective to the nature of the object/ item.

\section{REFERENCES}

[1] M. Garey, and D. Johnson, "Computers and intractability, a guide to the theory of NP- Completeness," Freeman, New York, 1979.

[2] K. Singh, and L. Jain, "An improved Heuristic for 2D Rectangular packing problem," Proceeding of IEEE International Advance Computing Conference, 2009, pp. 1185-1190.

[3] K. Singh, and L. Jain, "An empirical study of a modified Cheok-Nee's heuristic for 2d rectangular packing problem," Appejay. $J$ Management and Technology, Vol. 4, 2009, pp. 53-64.

[4] R. Morabito, and V. Garcia, "The cutting stock problem in a hardboard industry: a case study," Computers and Operations Research, Vol. 25(6), 1997, pp. 469-485.

[5] J. Puchinger, G.R. Raidl, G. Koller, "Solving a real-world glass cutting problem," In Proceedings of the 4th International Conference on Combinatorial Optimization (EvoCOP 2004), Coimbra, Portugal, Springer-Verlag. 2004, pp. 162-173.

[6] M.P. Johnson, and Z.E. Rennick, "Skiving addition to the cutting stock problem in the paper industry", SIAM REV 39, 1997, pp 472-483.

[7] S. Menon, and L. Schrage, "Order allocation for stock cutting in the paper industry," Operations Research, Vol. 50, 2002, pp. 324-332.

[8] G. Chryssolouris, N. Papakostas, and D. Mourtzis, "A decisionmaking approach for nesting scheduling: a textile case", Inter. J. Production Research," Vol. 38, 2000, pp. 4555-6427.

[9] A.J. Crispin, P. Clay, and G.E. Taylor, "Genetic Algorithm Coding Methods For Leather Nesting," Applied Intelligence, Vol. 23, 2005, pp. 9-20.

[10] A.J. Crispin, P. Clay, G.E. Taylor, T. Bayes, and D. Reedman, "Genetic algorithms applied to leather lay plan material utilisation," J. Engineering Manufacture, Vol. 217, 2003, pp. 17531756.

[11] Q. Weishuang, and J.L. Sanders, "A nesting algorithm for irregular parts and factors affecting trim losses," Int. J. Production Research. Vol. 25 No. 2, 1987, pp. 175-190.

[12] Christofides and C. Whitlock, "An Algorithm for Two-dimensional Cutting problems," Operations Research, Vol. 25 No.1, 1997, pp 3044.

[13] S.S. Israni, and Sander, J.L., "Performance testing of rectangular parts-nesting heuristic", Int. J. Production Research, Vol. 23 No. 3, 1985, PP. 437-456.

[14] S.C. Albright, W. Winston, and C.J. Zappe, "Data Analysis \& Decision Making with Microsoft Excel", Second Edition, International Student edition, Reprint Edition for sale in the in the Indian subcontinent only with CD of StatPro included in it, First Reprint 2004 by Thomson Asia Pte. Ltd., Singapore ISBN: 981-243-543-3, 2004

[15] K.V.S. Sharma, "Statistics Made Simple Do it Yourself on PC", ISBN-81-203-1741-6, $3^{\text {rd }}$ Printing, Eastern Economy Edition, Prentice-Hall of India Pvt. Ltd., October 2003.

Dr. Kawaljeet Singh is presently working as Director, University Computer Centre, Punjabi University, Patiala. Before this present job he has served as Professor \& Head, Department of Computer Science \& Engineering, Guru Nanak Dev University Regional Campus, Jalandhar. He had been given additional charge of Electronics and Communication Engineering Department also. He had been designated as Dean, Faculty of Engineering \& Technology, Guru Nanak Dev University, Amritsar. In that capacity he was also the Chairman of Research Degree of the Committee of Faculty. He had been also honorary Chairman, Board of Studies, Computer Applications, PTU Jalandhar. He has also been put as a member advisory committee to Industry-Academia association for Distance Education Programme of the PTU. He is/ was also the member of Board of Studies (Computer Engineering), PTU Jalandhar, Himachal Pardesh University, Summerhill (Shimla), Kurukshetra University, Kurukshetra, Chitkara University, HP. He did his MCA (1985-88) and Ph. D (2001) from Thapar University, Patiala. He has to his contribution 30 papers published in National/ International journals, 4 text books, 40 papers in national level conferences and 4 abstracts in international conferences. His subjects of interest are Simulation \& Modeling, Intelligent Databases, Theoretical Computer Science and Operating Systems. His total teaching experience to date is of 21 years. 
Leena Jain is graduated in Electronics and has dual master degree MCA and M.Sc (Mathematics). Presently, she is pursuing her Doctoral Research from University College of Engineering, Punjabi University, Patiala (India). Her interest area is in applications of optimization techniques and computing technology. She has more than Six years of experience in the academic field and also has more fifteen research publications in various national and international conferences and journals. 